\title{
CULTURAS LÚDICAS INFANTIS NA ESCOLA: ENTRE A PROIBIÇÃO E A CRIAÇÃO
}

\author{
Nair Correia Salgado de Azevedo ${ }^{1}$, José Milton de Lima ${ }^{2}$
}

${ }^{1}$ Doutora em Educação pela Universidade Estadual Paulista (UNESP), campus de Presidente Prudente, SP. Docente do Curso de Licenciatura em Pedagogia da Universidade do Oeste Paulista (UNOESTE), Presidente Prudente, SP.

${ }^{2}$ Livre Docente pela Faculdade de Ciências e Tecnologia, FCT (UNESP). Pós-Doutor pela Universidade de Salamanca, USAL (Espanha). Doutor em Educação pelo Programa de Pós-Graduação em Educação da Universidade Estadual Paulista (UNESP), campus de Marília. Docente no Departamento de Educação e no Programa de Pós-Graduação em Educação da Universidade Estadual Paulista (UNESP), campus de Presidente Prudente, SP.

\section{RESUMO}

Esse artigo é o resultado de uma Tese vinculada à linha de pesquisa "Processos Formativos, Infância e Juventude", do Programa de Pós-Graduação em Educação, da Faculdade de Ciências e Tecnologia da Universidade Estadual Paulista "Júlio de Mesquita Filho" (UNESP), Campus de Presidente Prudente/SP. O tema abordado relaciona-se à produção das Culturas Llúdicas Infantis no contexto escolar com enfoque no jogo e na brincadeira. Trata-se de uma pesquisa qualitativa, do tipo etnográfica, que usou de fundamentos da Sociologia da Infância para inserir as crianças como principais sujeitos durante esse processo acadêmico. Os procedimentos metodológicos usados para a coleta de dados foram: fotos e filmagens (muitas delas realizadas pelas crianças), registros em diários de bordo, entrevistas coletivas, registros no diário coletivo de brincadeiras e os textos ilustrados. Como objetivo geral, essa pesquisa buscou observar, descrever e interpretar as experiências lúdicas em diversos ambientes dentro de uma escola pública na cidade de Presidente Prudente/SP, assim como acompanhar o processo de produção das Culturas Lúdicas Infantis do contexto escolar estudado. As crianças nos indicaram que são muitas as ações de proibições das Culturas Lúdicas dentro da escola, mas também nos mostraram que o estímulo é possível por meio da mediação do professor. Concluímos que existem muitas razões para a proibição d7as manifestações culturais infantis nas escolas, porém nenhuma delas justifica tal posicionamento. Além disso, as crianças pedem que valorizemos suas opiniões e que possamos incluí-las nos processos educacionais de maneira que elas possam participar da Educação como um todo.

Palavras-chave: Educação. Sociologia da Infância. Culturas Infantis. Lúdico. Criança.

\section{CHILDHOOD CHILD CULTURES IN SCHOOL: BETWEEN THE BAN AND THE CREATION}

\begin{abstract}
This article is the result of a thesis linked to the research line "Formative Processes, Childhood and Youth", Graduate Program in Education, Faculty of Science and Technology, State University Paulista "Júlio de Mesquita Filho" (UNESP), in the city of Presidente Prudente/SP. The theme is related to the production of children's play cultures in the school context with a focus on play and play. It is a qualitative research, of the ethnographic type, that used the foundations of the sociology of childhood to insert the children as main subjects during this academic process. The methodological procedures used for data collection were: video filming and photos (many of them performed by children), logs in logbooks, press interviews, records in the collective play diary and illustrated texts. As a general objective, this research sought to observe, describe and interpret the play experiences in different environments within a public school, in the city of Presidente Prudente/SP, as well as to follow the production process of Children's Cultures in the studied school context. Children have pointed out that there are many bans on play cultures within the school, but they have also shown us that encouragement is possible through teacher mediation. We conclude that there are many reasons to prohibit children's cultural manifestations in schools, but none of them justify such a position. In addition, children ask us to value their opinions and we can include them in educational processes so that they can participate in Education as a whole.
\end{abstract}

Keywords: Education. Sociology of Childhood. Child Cultures. Playful. Child. 


\section{INTRODUÇÃO}

Quem nunca, revirando o baú de lembranças, foi capaz de sentir, mesmo que rapidamente, como era bom o tempo de brincar. Algumas pessoas, privilegiadas em nossa opinião, tem muitas situações lúdicas da infância para se lembrar, enquanto que outras não possuem muitas, apenas as mínimas capazes de absorvêlas por completo em frações de segundos. Para alguns, lembrar-se da infância pode não ser muito agradável caso tenham vivido momentos difíceis como a fome, o abandono, a miséria e o abuso. Para outras, infância significa deleite e tem até cheiro e sabor: cheiro de mato molhado e gosto de bolo de laranja. Mas, independente de ter sido uma infância mais ou menos sofrida, é certo que todas as pessoas já brincaram em algum momento.

Freire (2002) comenta que o tempo de brincar é eterno: ele nunca passa. Para o autor, o ser humano é uma criança infinita e por mais que o tempo passe, as marcas do rosto denuncie a idade e as tristezas contem suas histórias, a brincadeira nunca o abandona. Mas, se é verdade que o jogo nunca nos abandona, se é verdade que o tempo de brincar nunca passa, se é verdade que os brinquedos estão o tempo todo ali, nos olhando e nos esperando, o que faz com que escapemos do "Senhor do Jogo" e nos esqueçamos do êxtase que vivíamos durante as brincadeiras de infância? O que faz com que nos tornemos "mornos" e "insípidos" a ponto de pensarmos que brincar e jogar são "perda de tempo"?

Hoje, muitos problemas podem ser apontados pelos adultos como "desculpas" para a privação do lúdico na vida de nossas crianças: a violência urbana, a marginalidade, a desconfiança, a falta de tempo, etc.. Em algumas cidades do interior do Brasil, e aqui nos referimos mais especificamente ao interior do Estado de São Paulo, ainda é possível observar algumas práticas lúdicas consideradas "antigas", mais precisamente nas ruas, como jogar bola, brincar de esconde-esconde e pega-pega, andar de bicicleta, descer as ladeiras com carrinhos de rolimãs ou skates, soltar pipas... Porém, as ruas, principalmente dos grandes centros urbanos, têm sido cada vez mais privadas desses momentos.

É possível inferir, mediante todas essas afirmações, que hoje, para muitas crianças, a escola talvez seja o único local (ou o local privilegiado) de encontro com seus pares e com possibilidades de experienciar a ludicidade por meio do jogo e da brincadeira, mesmo que por raros momentos. Entretanto, vemos que em muitos contextos escolares as crianças cada vez mais são privadas dessas experiências.

Partindo desse pressuposto, podemos relacionar aqui o nosso problema de pesquisa, levantado por meio de nossa própria prática como professores da Educação Básica, convivendo com a rotina de muitas escolas e com muitos docentes dessa modalidade de ensino: a pouca valorização das Culturas Infantis, entendida por nós na mesma concepção de Borba (2005), como aquela que é construída e estabelecida pelas crianças nas relações com seus pares. Entendendo a ludicidade como um traço fundamental das Culturas Infantis (SARMENTO, 2004), o que percebemos é que o contexto escolar quase nunca se preocupa com o significado atribuído pelas crianças às práticas escolares - na maioria das vezes, não procuramos saber o que as crianças pensam, não ouvimos o que elas têm a nos dizer, não procuramos compreender o seu olhar.

O que propomos discutir nesse estudo é que, tais experiências lúdicas, embora muitos possam supor o inverso, não caminham contrariamente ao processo de aprendizagem das crianças no contexto escolar, mas elas são sim, uma facilitadora desse processo. A escola hoje demonstra um antagonismo às experiências lúdicas das crianças por supor a "perda de controle" sobre elas, além de outros motivos, como por exemplo, a priorização do ensino de conteúdos considerados "mais importantes" que outros - trata-se de algo que está enraizado na mente dos educadores brasileiros há muito tempo, desde o início do processo de escolarização em nosso país. Nesse contexto, as crianças são pouco ou quase nunca ouvidas e/ou respeitadas com relação a suas opiniões sobre esse assunto e em muitos outros emergentes nos processos educacionais, sociais e culturais que ocorrem na maioria dos contextos escolares.

O objetivo geral desse estudo foi o de observar, descrever e interpretar as experiências lúdicas em diversos ambientes dentro de uma escola pública, na cidade de Presidente Prudente/SP, e que se mostrassem relevantes para identificar o processo de construção das Culturas Lúdicas Infantis entre a proibição e a criação do ponto de vista do sujeito - nesse caso as crianças, alunos do $4 \% / 5$ o anos do primeiro ciclo do Ensino Fundamental, assim como acompanhar o processo de produção das 
Culturas Lúdicas Infantis do contexto escolar estudado.

\section{METODOLOGIA}

Essa pesquisa do tipo etnográfica e de caráter qualitativo foi realizada em uma unidade de educação pública municipal de I Ciclo do Ensino Fundamental, em Presidente Prudente/SP. A referida pesquisa também passou pela avaliação do Comitê de Ética e Pesquisa da Faculdade de Ciências e Tecnologia UNESP/Campus de Presidente Prudente, aprovada sob o protocolo de número 736.447 com data de 01/08/2014.

A unidade escolar atende crianças da Educação Infantil ao 5o ano do Ensino Fundamental, totalizando aproximadamente 375 alunos, situando-se na periferia da região oeste daquele município. Os dados foram coletados em duas turmas do 40 ano, no período de agosto a novembro de 2014 e também do período de março a setembro de 2015, com o mesmo grupo de crianças (já no 5o ano), totalizando 50 participantes. A pesquisa ocorreu durante vários momentos no ambiente escolar, como a sala de aula, o recreio, as atividades realizadas em oficinas pedagógicas, entre outros, pois um dos objetivos era perceber como se dava o processo de produção das Culturas Lúdicas Infantis desse grupo de crianças.

A observação e as anotações do diário de campo foram itens importantes dessa pesquisa, pois a intenção foi tentar perceber, de maneira mais fiel possível, como as vivências ocorriam no ambiente frequentado pelas crianças.

Angrosino (2009) argumenta que a observação, para que seja mais objetiva, precisa absorver e registrar tudo com a máxima riqueza de detalhes possíveis. Trata-se de um trabalho árduo, mas o pesquisador precisa usar os cinco sentidos para que sua percepção esteja cada vez mais aguçada. Portanto, as anotações feitas em campo devem ser transcritas imediatamente, com o maior número de detalhes e descrições ambientais que possam auxiliar no momento de interpretação dos dados.

Entretanto, os métodos precisam sofrer uma adequação quando os atores do processo da pesquisa são crianças, como foi o caso desse estudo. Podemos iniciar exemplificando as entrevistas que ocorreram na maioria das vezes em grupo, pela estratégia que Saramago (2001) denomina de "entrevistas-conversa". Trata-se de um método distinto da entrevista tradicional e é organizada em blocos temáticos.

Para iniciar as "entrevistas-conversa" de forma mais descontraída, sugere-se que elas sigam blocos temáticos, sendo o primeiro deles com um caráter "menos sério", mas não menos relevante para as crianças. Podemos dizer que um dos grandes segredos nesse método é o pesquisador ter sensibilidade para selecionar temas interessantes a cada contexto, pois assim a criança terá prazer em compartilhar suas opiniões.

Todas as "entrevistas-conversa" foram gravadas em vídeo pela pesquisadora. Muitos autores como Saramago (2001), Azevedo (2012), Ventorin e Poleze (2010) consideram de extrema importância a familiarização com o equipamento de fotografia e filmagem para que as gravações das entrevistas ocorram com mais tranquilidade. A primeira das "entrevistas-conversa" ocorreu após certo tempo de adaptação das crianças com a ação de filmar ou fotografar, portanto o processo de naturalização com o equipamento e as filmagens foi gradual e ao realizarmos a primeira delas não houve nenhum problema relacionado à presença das câmeras.

Podemos então definir as "entrevistasconversas" como uma espécie de entrevista semiestruturada e norteada por blocos temáticos. É importante reconhecer aqui que, o fato de usarmos blocos temáticos com palavraschave durante a intervenção nas entrevistas, não significou que a pesquisadora se absteve das perguntas norteadoras que toda entrevista semiestruturada requer. Embora as perguntas não sejam feitas da forma original como está no roteiro, pois as mesmas são apresentadas indiretamente sob a forma dos blocos temáticos, o roteiro é muito importante para que o pesquisador não se perca na condução das mesmas.

Portanto, o diferencial das "entrevistasconversas" parece estar na forma de expor as questões de planejamento que é realizada de maneira distinta dos métodos convencionais de entrevistas. Porém, esse estudo não abriu mão de realizar o que Manzini (2004) considera importante em toda entrevista: um roteiro semiestruturado para nortear esse processo, pois o mesmo serve para, além de coletar os dados, auxiliar o pesquisador a se organizar para esse processo de interação com os informantes, no caso, as crianças. 
A respeito do uso de desenhos e textos, esse estudo adotou uma estratégia denominada por Saramago (2001) de "textos ilustrados". A dinâmica dessa técnica ocorreu da seguinte forma: iniciamos a conversa com as crianças e lançamos um tema (que era escolhido conforme a triangulação dos dados) fazendo o registro desse tema na lousa. Após receberem uma folha própria para desenvolver a atividade, tiramos as dúvidas que surgiram. As crianças então desenharam e escreveram sobre $o$ tema individualmente podendo interagir com os colegas caso quisessem.

No caso desse estudo, as crianças receberam a folha avulsa contendo o local para desenhar e as linhas para escrever sobre o tema ${ }^{1}$. Em seguida, após esclarecimentos das dúvidas, as crianças foram orientadas a realizar a atividade individualmente na sua folha o que não impedia, caso eles quisessem, de sentar-se com colegas mais íntimos. As crianças demoraram cerca de uma hora e meia a duas horas para realizar toda a tarefa. Houve pouca intervenção por parte da pesquisadora nesses momentos e as crianças tiveram total liberdade de escolha também dos materiais a serem utilizados. Os temas abordados pelos dados coletados por meio dessa técnica serão apresentados no item "Resultados" desse artigo.

Também utilizamos uma técnica própria que chamamos de "Diário Coletivo de Brincadeiras". Baseando-nos em trabalhos como o de Delalande (2011) e Corsaro (2011), que consideram de extrema importância a participação ativa das crianças nas pesquisas, construímos um diário coletivo em que cada criança tivesse a oportunidade de levá-lo para sua casa e escrever ou desenhar sobre uma experiência importante para elas. Nesse diário, as crianças foram orientadas a registrar suas impressões como alegria, tristeza, satisfação etc., e que poderiam estar ou não relacionados à escola. Nesse caso, nossa intensão foi deixar as crianças livres para expressarem suas experiências lúdicas sob a forma pessoal de um diário.

Outra técnica utilizada nesse estudo foi a filmagem e que pensamos ter sido realizada aqui de forma bastante peculiar, pois geralmente, na maioria desses tipos de pesquisas, a filmagem é

\footnotetext{
${ }^{1}$ Conforme sugestão de Saramago (2001), as folhas entregues às crianças eram do formato A4, e continham os espaços adequados aos objetivos pretendidos, ou seja: zona de identificação; zona do texto; zona da ilustração. .
}

realizada pelo pesquisador com o intuito de captar mais detalhadamente o contexto pesquisado. Esse estudo optou também pelas filmagens realizadas pelas próprias crianças, então tivemos que adequar nossas percepções para depois realizar a interpretação do que as crianças queriam nos mostrar por meio dessa técnica.

Nesse sentido, o trabalho realizado pelo professor César Leite na Universidade Estadual Paulista/UNESP - Campus de Rio Claro/SP, intitulado "Ação, câmera e luz: entre imagens e olhares", que consiste em valorizar o protagonismo infantil das crianças na produção de imagens, tem se tornado um referencial para pesquisadores de estudos para e com a infância que pretendem utilizar essa técnica. $O$ referido trabalho é realizado com crianças de 8 a 11 anos em escolas públicas da cidade de Rio Claro/SP que filmam o que querem, sem instruções muito complexas $^{2}$, e o resultado foi bastante interessante: era preciso, primeiramente, uma mudança radical de enfoque. "Fazer pesquisa com crianças quando elas produzem as imagens é mudar radicalmente o protagonismo da cena. Porque não é mais o adulto aquele que olha e produz" (LEITE, 2014, p.2). .

Portanto, pensar em produções feitas pelas crianças em pesquisas acadêmicas, além de considerar a importante mudança de enfoque no qual o professor César Leite menciona, é necessário criar métodos de investigações com as crianças para que elas se sintam cada vez mais participativas no processo (DELGADO, 2011). Tal abertura foi adotada por esse estudo em vários momentos, e a produção de filmagens pelas crianças foi uma delas.

Porém, não basta apenas pensar que as filmagens realizadas pelas crianças é uma simples técnica de coleta de dados. O olhar do pesquisador ao interpretar tais dados oferecidos pelas crianças precisa estar atento àquilo que passa despercebido no cotidiano da pesquisa. "Oferecer câmeras fotográficas e filmadoras às crianças é se apresentar ao risco de caminhos por

\footnotetext{
${ }^{2}$ Segundo entrevista dada pelo professor César Leite ao Blog ComKids.com, o procedimento é bem simples: são dadas câmeras para que as crianças saiam pela escola e fotografem o que bem entendem, sem regras pré-definidas. A única instrução dada às crianças está relacionada ao manuseio das câmeras (como ligar, desligar, dar zoom etc.), mas segundo o professor, as crianças não possuem dificuldades nesse sentido devido ao fato de vivermos na era das mídias, e comenta ainda que muitas delas mexiam nas câmeras melhor que ele próprio. Disponível em: http://comkids.com.br/crianças-na-producao-de-imagens/. Consultado em: 17/10/2014.
} 
olhares desfocados, miradas longas, caminhos que insistem em mostrar atalhos, pés, chão" (LEITE, 2011, p. 125).

No início, ao assistir as filmagens realizadas pelas crianças, as corridas ofegantes, 0 chão em movimento, os gritos e toda aquela algazarra nos deixavam confusos. Tivemos que treinar esse olhar para perceber que, mais que simplesmente os pés das crianças, o que apareciam nas filmagens eram ações dotadas de significados que só percebemos após uma reflexão sobre as filmagens e as conversas que tínhamos com as crianças sobre o que elas filmavam. É a necessidade de se ouvir aquilo que não é verbal (SARMENTO, 2011).

Para Leite (2011), trata-se de um trabalho especial de tentar perceber entre imagens cortadas e entrecortadas o que as crianças têm a nos dizer. O "fora de foco" é o que na verdade nos interessa! São imagens que escapam de nossos controles e que nos expõem contextos semióticos diversos: esbarros, cortes de imagens, fragmentos, imagens esquecidas, imagens rápidas... Imagens que expõem "uma imagem corpo, um corpo sem fronteira, um corpo infantil que não se encerra em si, mas sim, que encontra modos de dizer a sua forma, de dizer a sua maneira a própria infância, aquilo que a infância nos diz" (LEITE, 2011, p. 131).

Dessa forma, a descoberta das cenas flagradas pelas câmeras revela o cotidiano das crianças. Trata-se de um cenário que temos que descobrir, pois são marcas históricas deixadas por todos.

\section{RESULTADOS}

Partindo nesse momento para os resultados obtidos no processo de coleta de dados com as crianças na escola e falando mais especificamente sobre a importância que os equipamentos de filmagem tiveram nesse processo, esse item exigiu, de nossa parte e da parte das crianças, certo grau de adaptação.

Começaremos pela descrição do início das filmagens que contou com alguns eventos interessantes. Além de explicar a elas como ligar, prender a câmera nas mãos, como trocar o modo filmagem pelo modo fotografia e demais regras, como por exemplo, escolher uma das crianças para que seja responsável pela filmagem (que poderia ser compartilhada ou não ${ }^{3}$ ), houve a

\footnotetext{
${ }^{3}$ A filmagem compartilhada foi uma ideia que surgiu durante as primeiras conversas com as crianças em que foi explicado como seria o procedimento de filmagem feito por elas. As crianças tiveram
}

necessidade de explicar a importância social da câmera para a pesquisa, pois no início as crianças ficaram um pouco receosas com relação ao que iriam filmar.

Um dos motivos que causou, num primeiro momento, esse receio, pode ser observado claramente na filmagem realizada por "Ski Safari" ", quando ele próprio diz "tudo o que a gente fala vai ficar gravado aqui, viu?" (Filmagem realizada por "Ski Safari", 14/08/2014) e, ainda, quando "Ski Safari" resolve compartilhar a filmagem com o colega "Anderson", presencia-se, mesmo que de forma inconsciente, uma atmosfera de vigilância às crianças, como veremos a seguir:

$\mathrm{Na}$ quadra algumas crianças correm, outras giram, outras apenas conversam... As duas turmas de 4o anos estão na quadra. "Ski Safari" pergunta a "Anderson" se ele quer filmar $e$ explica novamente ao colega como manusear a câmera. "Anderson" chega mais perto para filmar melhor seus colegas. Nesse momento, uma funcionária da escola passa, vê "Anderson" filmando e diz: "Gostei disso aí. Se você ver alguém batendo em alguém você filma, aí tem como provar 'Ó: foi Fulano que bateu em Ciclano'". "Anderson" responde: "Tá!". (Filmagem realizada por "Ski Safari", 14/08/2014).

Foi preciso esclarecer no dia seguinte a esse incidente, por meio de uma reunião com os alunos, quais eram, então, os verdadeiros objetivos das filmagens que seriam realizadas pela pesquisa:

Conversamos a respeito do ocorrido ontem durante a filmagem feita por "Ski Safari", quando uma funcionária alertou que, a câmera era ótima para "vigiar" o que eles estavam fazendo de "errado". Esclareci que não é esse o objetivo da pesquisa: ver o que ocorre de "certo" ou "errado"

\footnotetext{
algumas curiosidades, entre elas, se poderiam passar a responsabilidade de filmar para um colega, caso quisessem. Achamos oportuno e de bom senso deixar as crianças livres para tomarem essa decisão, e combinamos então que a criança sorteada ficaria responsável pela filmagem, mas não precisaria obrigatoriamente ser a única a filmar (Anotações do Diário de Bordo, 14/08/2014).

${ }^{4}$ Uma das primeiras ações com as crianças foi a de conscientizá-las sobre a importância do anonimato durante todo o processo de pesquisa. Explicamos a todos que era necessário que pensassem em um nome diferente do nome real, para que eles não pudessem ser identificados. Após o esclarecimento de algumas dúvidas das crianças, como por exemplo, se poderiam usar nomes de personagens, artistas ou outro nome comum, cada criança escolheu seu nome fictício. Nomes de atrizes, atores, brinquedos, jogadores de futebol, personagens de filmes, desenhos animados e até nome de jogos foram utilizados.
} 
enquanto eles brincam, e, ainda, que não ia mostrar a filmagem para ninguém além deles mesmos e que se fosse realmente necessário "vigiá-los" a escola estaria cheia de câmeras.

Nesse momento, "Percy Jackson", que foi o responsável pela filmagem no dia de hoje, perguntou: "Nair, e se sair uma briga mesmo o que acontece? Eu paro de filmar?".

Respondi que o fato de filmar ou não uma briga não seria eu quem decidiria isso e sim a criança que estivesse responsável pela filmagem naquele dia. Também salientei que pode sim acontecer de, durante alguma filmagem, ocorrer uma briga em que houvesse, talvez, até a necessidade da intervenção de um adulto, mas que eu também gostaria de saber como as crianças resolveriam esses conflitos. (Anotações do Diário de Bordo, 15/08/2014).

Nas filmagens que se sucederam após esse episódio, as crianças foram, aos poucos, deixando de ver a câmera como um objeto de vigilância, passando a vê-la com mais curiosidade. Isso é percebido em muitas filmagens em que aparecem crianças fazendo caretas, sorrindo e dando "tchauzinho".

Graue e Walsh (2003) também se utilizaram da filmagem de vídeo em seus estudos, e argumentam que há sim muitas vantagens nessa técnica, como o registro das expressões faciais das crianças, por exemplo, mas destacam como desvantagem a falta de discrição. Apesar de as câmeras de hoje em dia serem bem mais discretas que as descritas pelos autores (grandes e com tripés chamativos), nesse caso pudemos perceber que a indiscrição gerada pela câmera foi em outro sentido: no de vigiar e fiscalizar.

Para evitar esse constrangimento, a estratégia utilizada por esse estudo foi a de conversar com as crianças sobre o ocorrido. Como bem argumenta Martins Filho (2011), o pesquisador, ao criar os métodos de coleta de dados com as crianças, precisa estreitar cada vez mais os laços com elas, favorecendo as relações e o desenvolvimento de uma participação sensível às produções das crianças. No caso desse estudo isso contribuiu muito para que equívocos como esse pudessem ser esclarecidos rapidamente, evitando receio por parte das crianças em mostrar sua realidade, suas experiências e produções das Culturas Lúdicas que caberiam àquele grupo.

Encerradas as dúvidas sobre a função das câmeras em nossa pesquisa, começamos a perceber quais atividades eram consideradas relevantes para as crianças dessa escola e que, para elas, seriam dignas de ser filmadas. Apresentar a descrição de algumas dessas impressões não foi tarefa fácil e elencar apenas alguns entre vários registros gravados, filmados, fotografados, escritos ou desenhados que nos indicassem quais experiências seriam destacadas no contexto estudado exigiu um poder de síntese sem, porém, excluir nenhum detalhe importante.

Optamos por destacar algumas situações em que as crianças nos deixaram claro que, embora exista sim uma esfera de proibição visível em muitos contextos escolares, há também possibilidades de muitas experiências relevantes ao processo de produção das Culturas Lúdicas Infantis, seja por meio de estratégias próprias de viver as práticas lúdicas, seja por meio da mediação do professor.

Entre as atividades destacadas, iniciaremos por aquela que percebemos ser uma das atividades que mais encontram resistência por parte de alguns professores no contexto de sala de aula, mas dotada de muita importância pelas crianças: as atividades em grupo. As crianças enxergam nesses momentos a possibilidade de se trabalhar em parceria com os colegas e, dessa forma, aproveitar para conversar também sobre outras coisas ampliando o conhecimento que já tinham, tanto em termos de conteúdos abordados na escola, quanto em termos de conhecimentos relacionais ligados a seus colegas de sala.

"Dragon City": É melhor sentar em grupo porque às vezes nosso amigo do lado nos ajuda em muitas coisas.

"Giovanna Antonelli": A professora do terceiro ano dizia sempre que a gente vivia fazendo "panelinha". Hoje a gente conversa aqui dentro e brinca junto lá fora.

Nair: Pelo fato de ter melhorado a convivência entre vocês na sala de aula isso acabou refletindo lá no recreio, é isso?

Coro: Siiimmm.

Nair: O que houve esse ano de diferente pra isso mudar?

"Giovanna Antonelli": O fato, por exemplo, de a gente sentar junto na aula. Não tinha nada disso.

"Homem Aranha": Agora a gente brinca muito mais juntos no recreio, na quadra, aqui dentro, a gente forma grupo e aproveita pra conversar.

"Dulce María": A gente passou a ser mais amigo esse ano também por causa da brincadeira de pega-pega lá na escada. Antigamente só o "Raleigh", o "Homem Aranha" e o "Musculoso 2" 
que brincavam, agora um chama o outro $e$ quando a gente vê tem um monte brincando.

"Musculoso 2": A gente agora senta em grupo aqui e brinca em grupo lá fora". (Transcrição do relato oral obtido por meio da Entrevistaconversa realizada em 05/11/2014).

Envolver-se em atividades em grupo é sair da zona de conforto: movimentam-se as crianças e os móveis das salas, faz-se muito barulho, rompe-se com o silêncio tão cobiçado por muitos professores em suas aulas, enfim, dá bastante trabalho, pois promove muitos conflitos no início e até durante as atividades, portanto, é o tipo de proposta pedagógica que muitos professores evitam realizar.

As crianças participantes desse estudo, então, nos mostraram que a mediação do professor nas escolas é um diferencial. Percebemos, por exemplo, pela proposta do "Diário de Brincadeiras" que era, inicialmente, investigar quais eram os fatos mais interessantes ocorridos na escola (mas deixando as crianças à vontade também para falar de seus gostos pessoais, como brincadeiras e outros acontecimentos) que esse lócus foi retratado de forma muito rica, especialmente no que diz respeito à troca de experiências - mas essas experiências não estão relacionadas apenas a jogos e brincadeiras, pois o conteúdo formal escolar, mediado pelo professor, também é reconhecido por elas como algo prazeroso.

Por meio desses registros, é possível perceber que atividades com uma metodologia diferente, como técnicas artísticas, estratégias em grupo e novas propostas para atividades já conhecidas com a participação e mediação do professor parecem fazer mais sucesso nesse contexto. Parece-nos, então, que o problema muitas vezes não está na escola em si, mas na forma como são conduzidas muitas das relações ocorridas nela, que podem ser diretamente ligadas ao ensino e aprendizagem de conteúdos, mas também podem estar associadas às relações entre pares e entre professor e aluno.

O conteúdo e a atividade pedagógica passam a ganhar importância em nossas experiências escolares à medida que se aprofunda e se expande. Isso ocorre, entre outros, quando as pessoas envolvidas - o aluno e o outro (professor) - compartilham suas experiências. A capacidade de aprender e se interessar pelos conteúdos, portanto, tem na reciprocidade, respeito e admiração entre professores e alunos uma de suas alavancas para o sucesso (VILLELA, ARCHANGELO; 2015).

Pensamos ser esse o caso da relação entre professoras e alunos envolvidos no contexto desse estudo, como percebemos nos registros feitos pelas crianças na atividade de Texto llustrado:

"Eu lembro muito da professora... (mencionando o nome da professora do ano anterior), ela dava aulas muito legais e até hoje gosto dela. Quando vejo ela na escola dá mais vontade de voltar a estudar com ela, eu tenho várias lembranças" ("Talia", Texto llustrado).

"Minha experiência em pular corda foi muito legal. Quando eu for para o 60 ano vou sentir muitas saudades da minha professora, dos meus amigos e colegas. Eu amo todos!" ("Kátia", Texto Ilustrado).

"A gincana dos Jogos Indígenas foi a melhor! Eu estava feliz!" ("Fuleco", Texto Ilustrado).

"Eu gostei muito dos Jogos Indígenas. Agradeço por ter tido essa professora tão boa, ela é a melhor do mundo!" ("Musculoso 1", Texto Ilustrado).

Portanto, cabe à escola favorecer esse ambiente estimulador, capaz de aguçar a curiosidade das crianças pelos conhecimentos escolares. Segundo Villela e Archangelo (2015), a influência do professor é muito importante na vida de um aluno, pois além de ensinar os conteúdos e propiciar o desenvolvimento de crianças e jovens em nossas escolas, ele "envolve a tarefa de integrar as diferentes expectativas que esses trazem às experiências escolares que sejam significativas em seus vários domínios" (VILLELA; ARCHANGELO; 2015, p. 100). Em outras palavras: um bom professor se torna referência ou modelo intelectual capaz de abrir as portas dos estudos e conhecimentos às crianças e jovens que, por inúmeros motivos, estiveram fechadas até então.

\section{DISCUSSÃO}

Discutimos até aqui sobre a importância que as interações ocorridas no contexto escolar por meio do professor mediador possuem nos processos de produções das Culturas Infantis. Não podemos deixar de dar um destaque especial ao protagonismo das crianças, embora 
entendamos que esse protagonismo tenha ocorrido desde o início desse estudo.

Falar em protagonismo infantil significa ampliar e valorizar a participação das crianças em diversos níveis, a começar pelo reconhecimento da competência, da participação e da escuta das vozes das crianças nas pesquisas, na ciência, na educação, nos diferentes espaços sociais e até nas decisões políticas (SARMENTO, 2013).

Em todas as técnicas utilizadas para a coleta dos dados, aparece de forma relevante a presença do movimento e das relações sociais como fatos importantes para as crianças no ambiente escolar. Em Entrevista-conversa com as crianças, quando o assunto eram as filmagens realizadas, ficou evidente que eles gostaram bastante de filmar ações ocorridas fora do contexto de sala de aula. No caso das filmagens feitas na "Quadra", a justificativa das crianças em querer filmar tal ambiente, tão complexo e atraente ao mesmo tempo, foi o sentimento de liberdade que usufruíam quando estavam neste local. Independente de algum adulto querer podar as criações lúdicas das crianças, imediatamente elas realizam tentativas diferentes para que o processo de criação de novos jogos e brincadeiras aconteçam de uma forma ou de outra.

Nas tentativas que temos, muitas vezes, de privar as crianças dos movimentos não percebemos o quanto essas proibições afetam as relações que ocorrem dentro das escolas. Porém, ao perceberem tais oportunidades de se expressar, as crianças tentam aproveitar o máximo que podem, e isso é perceptível na fala de "Princesa Fairy" ao dizer "Lá a gente pode fazer qualquer coisa, brincar, aqui não, lá não tem lição" ao comparar algumas das atividades de sala de aula e as realizadas fora desse contexto.

Já com relação ao "Diário Coletivo de Brincadeiras" o que percebemos foi 0 protagonismo de muitas brincadeiras de rua nos registros das crianças, como "mamãe da rua", "esconde-esconde", além do futebol, andar de patins, de bicicleta, skate, patinete, pega-pega, jogos de tabuleiro, de cartas, soltar pipas, etc., e a vontade explícita de tornar muitas dessas brincadeiras de rua presentes também na escola, etc.

Refletindo sobre os registros contidos no "Diário Coletivo de Brincadeiras", percebemos a vontade que as crianças têm em manifestar suas Culturas Lúdicas que, muitas vezes, são obrigadas a deixar do lado de fora da escola. Podemos pensar que as crianças desse contexto ainda são privilegiadas no sentido de que a maioria delas ainda consegue brincar na rua com seus amigos e vizinhos, visto que esse estudo foi realizado em um município do interior do Estado de São Paulo, e numa região periférica da cidade. Assim, pensamos ser esse um dos fatores que propiciam tais vivências a essas crianças, mas sabemos que em muitas cidades grandes, o contexto urbano não favorece tais condições.

Foram muitas as percepções demonstradas pelas crianças no "Diário Coletivo de Brincadeiras" que manifestaram a satisfação das crianças em produzir e compartilhar suas culturas na escola. Com relação ao "Texto llustrado", a proposta era que as crianças pensassem numa situação ou experiência ocorrida que considerassem importante em todo o seu tempo de escola (que poderia ser desde a Educação Infantil) e demonstrassem pelo desenho e pela escrita o que elas sentiam quando se lembravam daquele fato. A atividade poderia ser realizada de forma individual (sentado sozinho) ou acompanhada (sentados em grupos), ficando essa decisão a critério das próprias crianças. Em ambas as turmas as crianças optaram por fazer essa atividade em grupos.

Muitas das respostas tiveram relações com jogos e brincadeiras no contexto escolar (englobamos nesse item, respostas como: jogos de Tênis de Mesa; competição de vôlei e queimada; aulas de Educação Física; Aulas de Dança; Brincadeiras diversas com os amigos; Atividades diferenciadas como os Jogos Indígenas e Soltar pipas), outras envolviam festas (no caso, Festas Juninas, Matinê de Carnaval e Festa de encerramento do ano).

A atividade de "Texto Ilustrado" procurou, então, resgatar na memória das crianças aqueles momentos dentro da escola que para elas causaram algum impacto. Algumas das lembranças regatadas foram de anos anteriores, como é o caso das aulas de Tênis de Mesa e alguns passeios externos organizados pela escola (Parques, Aeroporto, Batalhão da Polícia Militar, Teatro) - achamos importante ressaltar isso, pois percebemos que algumas atividades organizadas pelas escolas, como a saída do ambiente escolar em que estão acostumados e cujo objetivo é propor uma experiência mais concreta, pode se tornar muito eficaz.

No caso das crianças desse contexto, por exemplo, é perceptível pelos registros as 
lembranças de atividades que foram propostas quando ainda cursavam o 1 o ano do Ensino Fundamental. A dificuldade de as escolas organizarem esse tipo de atividade é muito grande, pois dependem de autorização das Secretarias de Educação, dos pais dos alunos, dos gestores, além do principal entrave para que esse tipo de atividade aconteça: a questão financeira, pois as escolas não têm condições de propiciar, mesmo que ocasionalmente, mais atividades como essas.

Se estamos dispostos a ver as crianças como cidadãos de direitos plenos, precisamos enxergá-las como capazes de opinar também com relação às áreas sociais, políticas e de assistência que lhe dizem respeito, e essa ação deve começar pela escola. Ferreira e Sarmento (2008) nos lembram de que as instituições para a infância tem sido conduzidas, na maioria das vezes, por ideias e ações adultas apenas, o que contribui para $\mathrm{O}$ predomínio de uma "(in)visibilidade" (FERREIRA; SARMENTO, 2008, p. 68) da infância - isso significa compreender que, apesar de as crianças existirem e estarem nas instituições, a inclusão de suas ideias nas tomadas de decisões é mínima, o que faz com que elas continuem em situação de invisibilidade e desconhecimento.

\section{CONCLUSÃO}

Essa pesquisa buscou compreender o processo de produção de Culturas Lúdicas Infantis no contexto escolar entre ações de proibição e criação. Entre os principais motivos para que a proibição continue presente, especialmente nos contextos escolares, destacamos o fato de que algumas pessoas julgam pertencer a culturas superiores à outras nesse caso, nós adultos muitas vezes elencamos, mesmo que inconscientemente, a cultura do adulto como superior às Culturas Infantis quando, por exemplo, impedimos as crianças de brincar, jogar, falar, de se expressarem pelo corpo, etc.. Percebemos nesse estudo que a criança viverá as Culturas Infantis quer o adulto permita ou não, então a pergunta central para nossa reflexão é: se isso ocorrerá, de uma forma ou de outra, porque não permitir que essas experiências aconteçam às claras?

Mostrar que o protagonismo infantil é possível, e o rompimento de paradigmas como "a criança enfant" (como um ser que não pensa e não tem ideias), parece ser um bom começo para superar a visão de que elas não possuem competência para opinar e participar ativamente dos processos que as envolvem. Se quisermos introduzir as crianças como sujeitos ativos nas pesquisas acadêmicas, precisamos dar voz a elas, - que implica ouvir suas opiniões, planejar algumas ações com elas, deixá-las a par de cada passo dado pela pesquisa, mudar o percurso caso seja necessário, ambientá-las cada vez mais ao contexto da pesquisa, enfim, é realizar uma nova pesquisa.

É obvio que uma pesquisa que se propõe a expor o mais fielmente possível a visão das crianças deve incentivá-las para que a participação aconteça de forma ativa nesse processo, mas isso não abstém o pesquisador de suas funções, como organizar esses dados com rigor, interpretá-los como o máximo de atenção ao detalhes fornecidos, cruzar os dados com o referencial estudado e argumentar suas ideias. Entre outras palavras, isso significa que as crianças nos oferecerão os dados, mas sua interpretação é feita pelo pesquisador, e quanto mais imerso, mais ambientalizado e mais disciplinada for a capacidade de organização e triangulação dos dados pelo pesquisador, maior será a concretização dos objetivos de seu estudo e menos equívocos interpretativos (o que compromete qualquer pesquisa de forma grave) ocorrerão.

Entre os principais objetivos dessa pesquisa estavam o de observar, descrever e interpretar as experiências lúdicas em vários momentos dentro de uma escola pública, que se mostrassem relevantes para identificar a criação das Culturas Lúdicas Infantis mesmo entre tantas proibições. Independente do motivo para que essas desculpas ainda permaneçam em nossas escolas em muitos momentos, sejam de ordem histórica, por comodismo, pela formação deficitária, pela falta de tempo, pelo fato de haver pouco espaço no currículo para as práticas lúdicas, pelo pouco investimento financeiro, pelo mínimo de reconhecimento do jogo e da brincadeira como importantes, pela ausência de políticas públicas que reconheçam as especificidades da ludicidade, etc., precisamos refletir e mudar algumas de nossas concepções pedagógicas a respeito dessa temática na Educação.

Ao retomar o tema dessa pesquisa - a produção das Culturas Lúdicas Infantis no contexto escolar, partimos do pressuposto de que as crianças são, muitas vezes, proibidas de se manifestar no ambiente em que muitas delas 
passam a maior parte de seu tempo diário: a escola. Mas, as crianças nos mostraram que ao mesmo tempo em que são proibidas de tantas coisas, elas sempre encontram um jeito de viver a infância, seja pela discreta brincadeira entre colegas no momento em que a professora não esteja olhando, nos poucos minutos de recreio em que a vigilância adulta se torna menos eficaz, ou na própria cabeça delas, por meio da imaginação.

Uma das principais conclusões desse estudo está diretamente ligada a essa questão: a mediação do professor se faz como um diferencial para propor experiências que incentivam o fluir e a produção das Culturas Lúdicas Infantis no ambiente escolar. É essa mediação docente que vai direcionar, muitas vezes, as ações, e essas podem pender para significações extremamente importantes e positivas.

O processo de produção das Culturas Lúdicas Infantis na escola é contínuo, e isso implica entendê-lo como algo dinâmico, que está sempre proposto a novas experiências e novas sensações. A criança não resiste a essa oportunidade de criar, recriar e deixar suas marcas culturais nos ambientes em que passam, independente de o adulto proibir ou não que tais manifestações aconteçam. As Culturas Lúdicas Infantis fazem parte da infância, e sendo a criança seu protagonista, fica impossível separálos uns dos outros. A tríade "Culturas Infantisinfância-criança" é inseparável, e onde um deles estiver presente, os outros ali também estarão.

O principal objetivo, que era saber como aconteciam as produções das Culturas Lúdicas Infantis entre a proibição e a criação em um determinado contexto escolar, nos foi mostrado pelas crianças: elas estão dispostas a continuar criando, mesmo que alguém atrapalhe, proíba ou tentem impedi-las de inventar, pois para quase toda regra existem exceções, e a exceção aqui parece ser a de não desistir nunca de criar. As Culturas Lúdicas Infantis nunca morrerão e estarão sempre se reinventando nas escolas em todos os cantos. Importa é que as reconheçamos como ações contidas na escola que não deve ser ignorada, pois se queremos melhorar a qualidade na educação precisamos primeiro valorizar tudo a respeito das crianças e da concepção de infância que precisamos ter.

E qual a concepção de infância ou o que é ser criança? Tentemos nos lembrar de nossas infâncias para responder a essa pergunta.
Pensamos que ser criança é descer a ladeira de bicicleta com a cara no vento; é fingir que somos fadas, reis, bruxas, policial e ladrão; é tomar sorvete em dia quente e deixá-lo escorrer pelos dedos, sujando toda a mão; é tomar bolada na cara quando a gente não sabe jogar muito bem futebol; é perder a pipa que, com tanto esforço, empinamos e realizamos manobras no ar; é procurar o último colega no esconde-esconde senão vou ter que bater cara de novo; é combinar um horário durante a aula pra entrar naquela sala de jogo da Internet que a gente tanto gosta pra jogar juntos, cada um na sua casa; é sentir o cheiro de livro novo; é cuidar dos materiais de escola como se fossem seus brinquedos. Ser criança, como diria Gonzaguinha, é ter pureza nas respostas; ou como diria o poeta Manoel de Barros é ser ligado em despropósitos; ou, ainda, ser criança, como diria Rubem Alves, é viajar na máquina do tempo... Podemos começar recordando cenas de nossa infância.

\section{REFERÊNCIAS}

ANGROSINO, M. Etnografia e observação participante. Tradução: José Fonseca. In: FLICK, U. (Coord.). Coleção pesquisa qualitativa. Porto Alegre: Artmed, 2009.

AZEVEDO, N. C. S. "Programa Cidadescola" no 10 ano do Ensino Fundamental em uma escola de Presidente Prudente: entre a ludicidade e a sala de aula. 2012. 213 f. Dissertação (Mestrado em Educação) - Universidade Estadual Paulista UNESP, Presidente Prudente, 2012.

BORBA, A. M. Culturas da infância nos espaçostempos do brincar. Niterói, 2005. 293 f. Tese (Doutorado em Educação) - Universidade Federal Fluminense, Niterói, 2005.

CORSARO, W. Sociologia da infância. Porto Alegre: Artmed, 2011, 384p.

DELALANDE, J. As crianças na escola: pesquisas antropológicas. In: MARTINS FILHO, A.; PRADO, P. D. (Orgs.). Das pesquisas com crianças à complexidade da infância. Campinas: Autores Associados, 2011, p. $61-80$.

DELGADO, A. C. C. Estudos socioantropológicos da infância no Brasil. Caminhos, problematizações e diálogos. In: MARTINS FILHO, A.; PRADO, P. D. (Orgs.). Das pesquisas com 
crianças à complexidade da infância. Campinas: Autores Associados, 2011, p. 181 - 210.

FERREIRA. M.; SARMENTO, M. J. Subjectividade e bem estar das crianças: (In)visibilidade e voz. Revista Eletrônica de Educação, São Carlos, v.2, n.2, p. 60-91, nov. 2008.

FREIRE, J. B. O jogo entre o riso e o choro. Campinas, Autores Associados, 2002, 125 p.

GRAUE, M. E.; WALSH, D. J. Investigação etnográfica com crianças: teorias, métodos e ética. Lisboa: Fundação Calouste Gulbenkian, 2003.

LEITE, C. D. P. Infância, experiência e tempo. São Paulo, Cultura Acadêmica, 2011.

LEITE, C. D. P. Tempo, experiência e linguagem: territórios de um devir na infância. Childhood $\epsilon$ Philosophy, Rio de Janeiro, v.6, n.11, p. 70-85, jan./jun. 2014.

MANZINI, E. J. Entrevista semiestruturada: análise de objetos e de roteiros. In: SEMINÁRIO INTERNACIONAL SOBRE PESQUISA E ESTUDOS QUALITATIVOS, 2004, Bauru. Anais. Bauru: USC, 2004, v.1, p. 1-10.

MARTINS FILHO, A. J. Jeitos de ser crianças: balanço de uma década de pesquisas com crianças apresentadas na Anped. In: MARTINS FILHO, A.; PRADO, P. D. (Orgs.). Das pesquisas com crianças à complexidade da infância. Campinas, Autores Associados, 2011, p. 81- 106.

SARAMAGO, S. S. S. Metodologia de pesquisa empírica com crianças. Sociologia, problemas e práticas, n.35, p. 9-29, 2001.

SARMENTO, M. J. As culturas da infância nas encruzilhadas da segunda modernidade. In: SARMENTO, M. J.; P; CERISARA, A. B. (Orgs). Crianças e miúdos: perspectivas sociológicas da infância e educação. Porto: Asa Editores, 2004, p. 9-34.

SARMENTO, M. J. Conhecer a infância: os desenhos das crianças como produções simbólicas. In: FILHO, A. J. M.; PRADO, P. D. (Orgs.). Das pesquisas com crianças à complexidade da infância. Campinas, Autores
Associados, 2011, p. 27-60.

SARMENTO, M. J. Infância contemporânea e educação infantil: uma perspectiva a partir dos direitos da criança. In: SALMAZE, M. A.; ALMEIDA, $O$. A. Primeira infância no século XXI - direito das crianças de viver, brincar, explorar e conhecer o mundo. Campo Grande: Oeste, 2013, p. 131-148.

VENTORIN, S.; POLEZE, G. M. L. Narrativas de imagens do recreio escolar. In: ENCONTRO NACIONAL DE DIDÁTICA E PRÁTICA DE ENSINO. Convergências e tensões no campo da formação e do trabalho docente: políticas e práticas educacionais. 2010, Belo Horizonte. Anais... Belo Horizonte, 2010, p. 26-37.

VILLELA, F. C. B; ARCHANGELO, A. A escola significativa e o aluno diante da atividade. São Paulo: Loyola, 2015.

Recebido para publicação em: 11/09/2017

Revisado em: 14/09/2017

Aceito em: 23/09/2017 